\title{
Art Wonder: Using Technology Enhanced Learning (TEL) and Wearable-Enhanced Learning (WELL) in the Museum Context to Enhance their Visitors' Experience
}

\author{
Francesca Guerrera \\ Learning Technology Research Centre (LTRC) at Ravensbourne \\ 6 Penrose Way, Greenwich Peninsula, London SE10 0EW, UK \\ f.guerrera@rave.ac.uk
}

\section{INTRODUCTION}

Art Wonder aims to enablemultiple novel ways of enhancingvisitor experience in exhibition spaces. Material interaction and exhibition' itineraries are the focus of the investigation and finding appropriate methods for connecting the visitors with one another.

The theoretical basis of this work comes from Oxford Prof.Théodore Zeldin, who demonstrates that Art is capable of fostering dialogue among different cultures and languages. $\mathrm{He}$, at the same time, warns us, that if we want to grow again in the future, we need to foster the dialogue between cities and suburbs, professions and passions; to go beyond individuals isolation and stop distrusting our counterparts. He gives the specific example of how people are usually suspicious towards counterparts who have a very different job in respect to them, and explains how the aptitude towards what is 'different from what we are already familiar with' has to be changed. Prosperity and creativity depend on the interaction between very diverse competences and ideas.

Therefore, the discipline of Art can be interpreted as an extension of the idea of civic service through the decreasing of isolation amongst individuals. To establish good communication capable of building trust, people need to leave the comfort of their usual territory.

\section{IMPLEMENTATION}

Art Wonder began by initially developing a platform for museums and an app for users; further implementations will be tested including the use of wearables, VR and ARfeatures.
On the museum side, our goal is to supply an infrastructure with a user-friendly interface that aims to become a daily tool for the people who work in the museum, for developing their cultural and educational offer. We will use the cloud to give them the opportunity to store visitor information and the content that visitors will need to access.

On the visitors side, we want to offer two opportunities. The first will be to access the exhibitions and their materials in a multi-channel way. The second is to enable visitors to the museum to connect using an internal geo-location solution. Four key parameters will be involved: the visitors preferred spoken language, profession, age, and estimated time of the visit.

\subsection{Concerns and Opportunities}

There is usually a shared concern regarding mobile devices in museums, which is that they tend to isolate visitors and inhibit social interaction (vom Lehn \& Heath 2005). There is, at the same time, evidence to suggest that many of the problems with digital devices in museums may be tackled with improved contextual designs that are in tune with museum learning research. As Falk and Dierking (2000) suggest, when designed well, mobile digital technologies can enable visitors to customise their visit, to extend the experience beyond the museum, and 'layer multi-sensory elements within the experience' through the use of digital media.

Furthermore, the use of mobile devices in museums as a learning resource performs five functions (Fleck et al. 2002): providing information about exhibits; providing instructions for how to use the exhibits; helping visitors communicate with each other; exhibition guidance in a meaningful order; and recording information for later retrieval. 


\subsection{The Global and the UK Market}

Another great opportunity is the market: the museums market value worldwide is worth $£ 2.6 \mathrm{bn}$ : out of this amount, offline tickets are $£ 1.8 \mathrm{bn}$, online tickets $£ 217 \mathrm{~m}$, while audioguides and bookshop value reaches $£ 580 \mathrm{~m}$. There are about 55,000 museums in the world, approximately 2,000 in each of the main European countries. Taking into consideration the UK, Italy, France and Germany, the annual number of visitors exceeds 280 million.

In the UK, as mentioned on the Museums Association FAQs section,"eight of the top ten visitor attractions are museums. The UK has five of the top 20 most visited art museums in the world (more than any other country). It is estimated that there are about 2,500 museums in the UK, of which over 1,800 have been accredited. In a consumer survey, museums and galleries scored the highest satisfaction rating of any public service, leading to the conclusion that investment in museums and galleries has paid off handsomely, with a world-class satisfaction rating'. There are no up-to-date figures for total visits in the UK but it is likely to exceed 100 million a year".

\section{THE ROLE OF TEL AND WELL}

In regard to Technology Enhanced Learning (TEL), mobile learning is at the forefront of a lot of research. Mobile phones are one of the most familiar and easily accessible technologies that museum visitors can use to augment their educational experiences, both before, during, and after their visit. Gammon \& Burch (2008) show in their research that visitors familiarity with the technology is key to the successful design and implementation of mobile devices in museums.

Several researchers point to the quick adoption of mobile phones by teens in particular. An interesting example of TEL is given by the Gidder (Groups in Digital Dialogue) project: a study of high school students learning about modern and contemporary Art History, in activities and technologies that move across classroom and museum contexts (Pierroux 2007). In regard to Wearable Enhanced Learning (WELL) this field is beginning to have an impact in Museum interaction design. One example is called Finger Reader which is a device, developed by the MIT Media Lab (2014), that fits on your index finger like a ring: if you trace a page with your finger, it will read it out loud for you. It can be used to assist children, the elderly, visually-impaired people, and second-language learners with reading labels, business cards, menus in a restaurant, prescriptions, or any other type of printed text.

\subsection{Next Steps}

The first tests will be carried out at the Victoria and Albert Museum (V\&A) and the Science Museum, in London. There is a high interest, from our side, in testing the app and the TEL and WELL methodologies with a young audience, reason for which we are asking the V\&A Museum of Childhood to cooperate with us. The goal is to be able to show you the results in one year from now.

\section{REFERENCES}

Falk, J. \& Dierking, L. D. (2000) Learning from Museums: Visitor Experiences and the Making of Meaning. Altamira Press, Walnut Creek, Ca.

Fleck, M., Frid, M., Kindberg, T., O'Brien-Strain, E., Rajani, R., \& Spasojevic, M. (2002) From Informing to Remembering: Deploying a Ubiquitous System in an Interactive Science Museum. HP Laboratories, Palo Alto.

Gammon, B. \& Burch, A. (2008) Designing mobile digital technology for museum visitors. In Tallon, L., Walker, K. (eds), Digital Dialogues: Personal technologies and the museum, Altamira Press, Walnut Creek, CA.

MIT Media Lab (2014) Fingerreader. Fluid Interfaces, MIT Media Laboratory, USA. http://fluid.media.mit.edu/projects/fingerreader (retrieved 9 April 2015).

Museums Association (2014) Frequently Asked Questions (FAQs).

http://www.museumsassociation.org/about/frequent ly-asked-questions (retrieved 7 April 2015).

Pierroux, P. (2007) Mobility in Learning. Making Meaning Across Classroom and Museum Settings. IADIS International Conference on Mobile Learning, 5-7 July, Lisbon, Portugal.

Smith, K. J. (2009) The future of mobile interpretation. In Trant, J. and Bearman, D. (eds), Museums and the Web 2009: Proceedings. Toronto: Archives \& Museum Informatics. http://www.archimuse.com/mw2009/papers/smith/s mith.html (retrieved 7 April 2015).

vom Lehn, D., Heath, C. (2005) Accounting for new technology in museum exhibtions. International Journal of Arts Management, 7(3), 11-21. 